\begin{tabular}{|l|c|} 
Proceeding of the $^{\text {th }}$ ICEE Conference 3-5 April 2018 & NRA \\
Military Technical College \\
Kobry El-Kobbah, \\
Cairo, Egypt
\end{tabular}

NRA-3

\title{
Analysis of naturally occurring radioactive materials in environmental samples using gamma spectrometry
}

\author{
Omar Abo Bakr Omar ${ }^{1}$, Mohamed A.E. Abdel-Rahman ${ }^{1}$, Sayed A.El-mongy ${ }^{2}$
}

\begin{abstract}
:
Natural radioactivity exists everywhere around us in soil, air, water, and atmosphere and even in our bodies. Radiological background levels especially for vital locations are of great importance to our country nuclear program. EL-Dabaa site, at which the first Egyptian nuclear power plant will be constructed, is strategic area to be monitored before the beginning of the plant experimental and commercial operation.

The aim of this study is to evaluate the radioactivity levels and its radiological hazard indices especially in the zones around the NPPs; exclusion zone, low population zone and high population area (El-Dabaa old and new town). Many soil and shore sediment samples were collected from these areas. They were prepared and then analyzed using HpGe spectrometer. The calculations of activity concentration (Ac) of natural radionuclides ${ }^{238} \mathrm{U},{ }^{232} \mathrm{Th}$ decay series and ${ }^{40} \mathrm{~K}$ were carried out. Based on the results obtained, the hazard indices (air absorbed gamma dose rate $\mathrm{D}$, annual effective dose $\mathrm{E}$, excess life time cancer risk ELCR) indoor and outdoor also ( Ra equivalent Raeq and internal and external hazard index Hin,Hex) also ( gamma index I $\gamma$ and alpha index I $\alpha$ ) were estimated. The man-made radionuclide ${ }^{137} \mathrm{Cs}$ was also measured. The results are tabulated, plotted, discussed and compared with the national and international levels and limits.
\end{abstract}

\section{Keywords:}

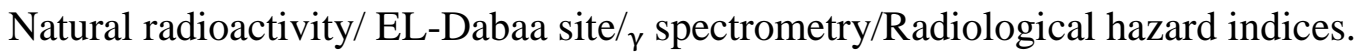

\footnotetext{
${ }^{\mathrm{T}}$ Nuclear Engineering Department, Military Technical College, Cairo Egypt

${ }^{2}$ Nuclear and Radiological Regularity Authority
} 


\section{Military Technical College \\ Kobry El-Kobbah, Cairo, Egypt}

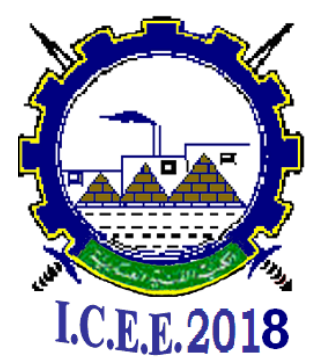

$9^{\text {th }}$ International Conference on

Chemical \& Environmental Engineering

3-5 April 2018

\section{Introduction}

Radioisotopes is a word consists of two parts the first one is radio which mean emit radiations like (alpha, beta, gamma ....etc.) radiations. The second part isotopes which are the atoms that have the same atomic number $\mathrm{Z}$ which means same number of protons or electrons and thus identical chemical properties but different atomic mass A or number of neutrons $\mathrm{N}$ and as a result different physical properties. Finally, radioisotopes nuclei have a special property they emit energy in the form of ionizing radiation to attain a more stable configuration. And its origin in the environment may be naturally or artificially[1]. Natural sources of radioisotopes or radionuclides falls into three main categories the first is primordial (terrestrial) radionuclides such as $\left({ }^{238} \mathrm{U}-{ }^{232} \mathrm{Th}-{ }^{235} \mathrm{U}\right)$ which exist since the creation of the universe. The second is secondary radionuclides that are the decay series products of the three main primordial radionuclides uranium, thorium and actinium series. The third is Cosmo-genic radionuclides such as $\left({ }^{14} \mathrm{C}-{ }^{3} \mathrm{H}-{ }^{7} \mathrm{Be}\right.$....etc. $)$ which were formed due to the interaction between cosmic rays and atmosphere [1] .

Artificial (man-made) sources of radionuclides falls into two main categories, the first is from worldwide fallout from nuclear weapons testing or using the second is due to nuclear power plants working or accidents like $\left({ }^{137} \mathrm{Cs}-{ }^{90} \mathrm{Sr}-{ }^{239} \mathrm{Pu}\right)[2]$.

Naturally, Occurring Radioactive Materials (NORMs) have always been present in our world since its beginning.

In this study, we will deal mainly with terrestrial radionuclides as main source of (NORMs) in the environment which including ${ }^{40} \mathrm{k}$ (half-life $26 \times 10^{9}$ years) which is widely distributed in the earth's crust and exist in measurable quantities in many building materials and vegetables or fruits. In addition, there are four naturally independent decay chains each one is headed with a very long lived radionuclide parent and associated with a number of intermediate radionuclides daughters and ended with a stable radioisotope and they are uranium, thorium, actinium and neptunium [3] .

The Neptunium series has decayed away and, thus cannot be seen any more because the halflife of Neptunium is less than the age of earth $\left(4.5 \times 10^{9}\right.$ years $)$. Only the residual isotope from this decay chain, Bismuth- 209 can be observed today [3].

In gamma-ray spectroscopic studies of these decay series, most frequently decays from the daughter can be observed for example, in the Thorium $\left({ }^{232} \mathrm{Th}\right)$ series gamma-ray decays from ${ }^{208} \mathrm{Tl}(583.19 \mathrm{KeV}),{ }^{228} \mathrm{Ac}(911.2 \mathrm{KeV}-968.97 \mathrm{KeV}),{ }^{212} \mathrm{pb}(238.63 \mathrm{KeV})$. in the (U238) series gamma-ray decays from, pb214 (351.92KeV-295.4KeV) and ${ }^{214} \mathrm{Bi}$ (609.31 KeV-1120.28KeV). These isotopes can be founded in rocks and soil samples. Radium-226 produces Radon-222 via alpha decay, which diffuses from the earth into the atmosphere producing a number of short-lived radionuclides. In addition, the man-made radionuclide ${ }^{137} \mathrm{Cs}$ has a line $(661.66 \mathrm{KeV})$ which can be observed in gamma ray spectra [3] 


\section{Military Technical College \\ Kobry El-Kobbah, Cairo, Egypt}

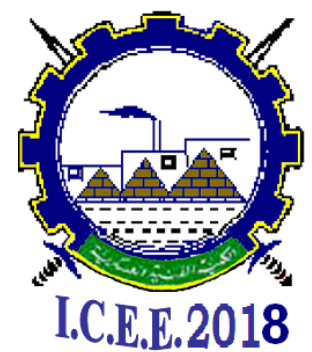

$9^{\text {th }}$ International Conference on

Chemical \& Environmental

Engineering

3-5 April 2018

\section{Experimental work}

\subsection{Measurements Arrangement and set-up}

The collected samples were analyzed using gamma ray spectroscopy technique based on a high-purity germanium (HpGe) detector of $\sim 50 \%$ efficiency. The HpGe detector, with its built-in preamplifier, is operated at high voltage power $\sim 3 \mathrm{kV}$. For cooling the $\mathrm{Ge}$ crystal, it was in contact with cold finger which is fully immersed in liquid nitrogen at $\left(-77^{\circ} \mathrm{C}\right)$ thermally isolated under vacuum in cryostat to reduce the noise of leakage current. The output signal was connected to spectroscopy shaping amplifier followed by a multi-channel analyzer (MCA) with 16384 channels. To avoid contribution of the background radiation and various natural radiation sources in nearby surrounding to the measured activity of samples, a lead shield with approximately $10 \mathrm{~cm}$ thick with an inner layer of $1 \mathrm{~mm}$ tin and $1.6 \mathrm{~mm}$ copper to minimize the participation from $\mathrm{Pb} \mathrm{X}$-ray florescence and to inhibit the effect of X-rays peaks were used [4].

Finally, the spectra of all samples and standard sources were analyzed using GENIE 2000 software of the used HpGe detector (relaive efficiency $\geq 50 \%$ and resolution $\leq 1.9$ at $1.33 \mathrm{MeV})$.

To measure the background for the HpGe detector system, an empty Marinelli container with an identical shape to the sample, was placed on the top of the detector and counted three times. All the measurements for background, samples and standard / reference materials have the same counting time, 86400 seconds ( 24 hours). The spectra of all the samples and standard or reference sources were analyzed with Genie2000 software in the same way and with the same geometry as was done for the background counting.

\subsection{Detector Characteristics}

\subsubsection{Energy Calibration}

Energy calibration of the HpGe detector system was performed to obtain a relationship between the channel number of the peaks position in the spectrum and the corresponding gamma ray energy. It was performed using two point standard sources of Co-60, Cs-137, and mixed point source of Eu152, Eu154,Eu155, with activities of $1 \mu \mathrm{Ci}$ for Co-60, $\mathrm{Cs} 137$ and $0.45 \mu \mathrm{Ci}$ for Eu mixed source. The standard sources energy range is from 121 $\mathrm{keV}$ to $1407 \mathrm{keV}$. The standard sources were placed on the top of the HpGe detector and detector spectrum was obtained with a counting time of $1800 \mathrm{sec}(30 \mathrm{~min})$ to obtain high counts with good statistics. A plot between the channel number and the energy was obtained using the following linear equation [5] and figure 2.1.

$$
\text { Energy }(\mathrm{keV})=-6.636 \times 10^{-3}+0.1748 \times \text { channel }
$$


Military Technical College Kobry El-Kobbah, Cairo, Egypt

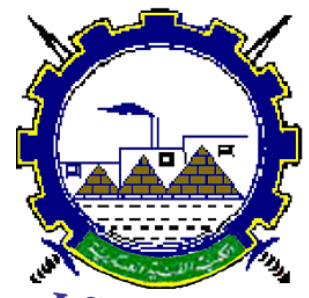

I.C.E.E.2018 $9^{\text {th }}$ International Conference on

Chemical \& Environmental

Engineering

3-5 April 2018

\subsubsection{Efficiency Calibration}

The absolute photo-peak efficiency, which depends on many parameters like the (sourcedetector geometry - gamma energy - density - distance between the source and detector specifications of the used HpGe detector, was measured. The absolute photo peak efficiency of the HpGe detector was calculated.

The efficiency calibration of the detector is carried out using IAEA standard radionuclide source (RGU-1) as shown in Table (1) the standard source is counted three times for $86400 \mathrm{sec}$ and then Microsoft excel program is used to calculate the efficiency at every gamma energy using the above equation. Genie2000 program was used and the results obtained as follow (Fig.2.2):

Using IAEA (RGU-1) standard source of almost the same structure and geometry as the samples allows the elimination of the effects of variation of the geometry solid angle $\Omega$. In other words, the value of $\Omega$ was neglected in these activity calculations. The obtained (RGU-1) efficiency-energy was used to calculate the activity of Th232 in the IAEA reference material (RGTh-1). This was done for the confirmation of the obtained results. The two gamma lines $(911.2 \mathrm{KeV}-968.97 \mathrm{KeV})$ of Th232 were used for activity calculations based on following equation (1):-

$$
A_{C}=\frac{c}{I_{\gamma(E)} \times t \times \xi_{a b s} \times m}
$$

Where:

$\xi_{a b s}$ Is the detector photo peak efficiency at certain energy and known measurement condition

$C$ Is the number of counts at certain region of interest in the spectrum - the number of counts in background spectrum at the same region of interest.

$I_{\gamma(E)}$ Is the emission probability of gamma having certain energy per disintegration.

$\boldsymbol{t}$ Is the counting time (86400 S) $24 \mathrm{hrs}$.

$A_{c}$ Activity concentration of the reference source $(\mathrm{Bq} / \mathrm{kg})$

$m$ Mass of the reference source in $(\mathrm{kg})$ 


\section{Military Technical College \\ Kobry El-Kobbah, Cairo, Egypt}

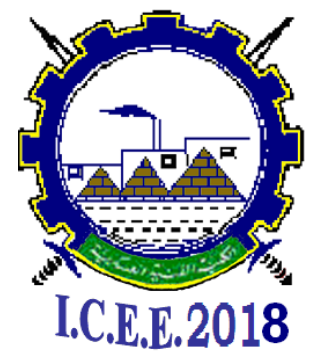

$9^{\text {th }}$ International Conference on

Chemical \& Environmental

Engineering

3-5 April 2018

The obtained results of activity concentration were in good agreement with the reference material certificate with error from the mean value (10\%).

\subsection{Samples collection and preparation}

The aim of this study is to evaluate the radioactivity levels and its radiological hazard indices especially in the zones around the NPPs; exclusion zone, low population zone and high population area (El-Dabaa old and new town). Twenty-four soil and 6 shore sediment samples were collected from these areas. The samples were collected from the top surface layers and then packed in labeled plastic bags with date and location; they were then transported to the nuclear spectroscopy laboratory in Cairo for analysis then the preparation steps was carried out as follow:

Sieving step: the collected samples sieved using a $2 \mathrm{~mm}$ mesh to obtain a uniform particle size and because no radioactive materials exist on large size of sand texture.

Drying step: The sieved samples were dried in a drying oven at $105^{\circ} \mathrm{C}$ until removal of the moisture because the existence of moisture may affect the samples analysis results as it may act as attenuation material.

The prepared samples were then weighted and transferred to the used Marinelli containers and sealed to be kept undisturbed for 28 days to attain secular equilibrium [5].

\subsection{Background Spectrum and Minimum Detectable Activity (MDA) calculation and results}

When dealing with low activity samples specially environmental samples it is necessary to determine the MDA of the counting system hence an empty Marinelli beaker was used to estimate the background radiation. The Marinelli container of the background sample has the same geometry applied for the site samples it was counted 3 times for $86400 \mathrm{~S}$ (24hrs) and the average background counts for every peak was obtained. MDA can be calculated according to equation (2) [4].

Where:

$$
M D A=\frac{4.66 \sqrt{B \cdot G \cdot C}}{I_{\gamma(E)} \times t \times \xi \times m}
$$

$\xi$ The detector photo peak efficiency at certain energy and known measurement

$\zeta$ abs condition

B.G.C The number of counts at certain region of interest in the back ground spectrum

$I_{\gamma(E)}$ The emission probability of gamma having certain energy per disintegration

$\boldsymbol{t}$ The counting time (86400 S) $24 \mathrm{hrs}$ 
Military Technical College

Kobry El-Kobbah, Cairo, Egypt

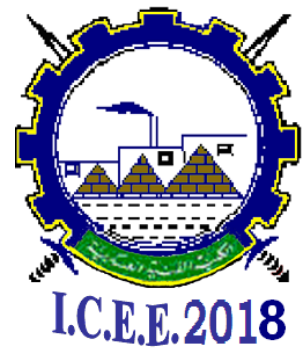

$9^{\text {th }}$ International Conference on

Chemical \& Environmental

Engineering

3-5 April 2018

MDA minimum detectable activity of certain energy $(\mathrm{Bq} / \mathrm{kg})$

$m$

The mass and assuming an average mass of all samples equal to $0.3 \mathrm{~kg}$

There is some photo peaks will be used to calculate the activity concentrations of ${ }^{238} \mathrm{U}$ (226Ra), ${ }^{232} \mathrm{TH}, 40 \mathrm{~K}$ and ${ }^{137} \mathrm{Cs}$ hence I should estimate the MDA was estimated for these lines and the results are given as follow table (2):

\section{Results and Discussion:}

\subsection{Activity concentration results}

The activity concentration of $238 \mathrm{U}$ in the samples was determined using the $\gamma$-ray of its decay daughters such as $226 \mathrm{Ra}$ and its daughters; $214 \mathrm{pb}(351.92 \mathrm{KeV}-295.4 \mathrm{KeV})$ and $214 \mathrm{Bi}(609.31 \mathrm{KeV}-1120.28 \mathrm{KeV})$ and also can be estimated using 234Th $(63.29 \mathrm{KeV})$ and $234 \mathrm{~Pa}(1001 \mathrm{KeV})$. Also, the activity concentration of $232 \mathrm{Th}$ was estimated using the $\gamma-$ ray of its decay daughters such as $208 \mathrm{Tl}(583.19 \mathrm{KeV}),{ }^{228} \mathrm{Ac}(911.2 \mathrm{KeV}-968.97 \mathrm{KeV})$, ${ }^{212} \mathrm{~Pb}(238.63 \mathrm{KeV})$. The activity concentration values were averaged assuming the secular equilibrium. The $235 \mathrm{U}$ was not identified clearly in all spectra of the samples and background spectra. On the contrary, global man-made 137Cs $(661.6 \mathrm{KeV})$ and also $40 \mathrm{~K}$ $(1460.83 \mathrm{KeV})$ was clearly observed in all the samples and the results of the analyzed soil samples are given in the following Table (2).

\subsection{Results of radiation hazard indices calculations.}

The main purpose of radiation hazard indices calculations are to allow us having a conclusion about the health of exposed person or environment [8] at EL-Dabaa area for indoor and outdoor radiation hazard due to calculated activity concentration of specified radionuclides such as 238U, 232Th and 40K [9]. The values of Absorbed Gamma Dose Rate (D), Annual Effective Dose Rate Equivalent (E) (AEDRE),External and Internal Hazard Indices (Hex and Hin) and gamma index $(\mathrm{I} \gamma)$ and alpha index $(\mathrm{I} \alpha)$ and excess life time cancer risk (ELCR) are all related to the activity concentrations of 238U, 232Th and $40 \mathrm{~K}$ for the measured samples, as can be calculated in the following equations [10].

\subsubsection{Indoor radiological hazard indices}

Indoor air absorbed gamma dose rate (Din) is the dose imparted by the activities of ${ }^{226} \mathrm{Ra}$,

${ }^{232} \mathrm{Th}$ and ${ }^{40} \mathrm{~K}$ present in any material used for the construction purpose like sand. The three conversion factors considered are; $0.92\left(\mathrm{nGy} \mathrm{h}^{-1} / \mathrm{Bq} \mathrm{kg}^{-1}\right)$ for ${ }^{226} \mathrm{Ra}, 1.1\left(\mathrm{nGy} \mathrm{h}^{-1} /\right.$ $\mathrm{Bq} \mathrm{kg}^{-1}$ ) for ${ }^{232} \mathrm{Th}$ and $0.081\left(\mathrm{nGy} \mathrm{h}^{-1} / \mathrm{Bq} \mathrm{kg}^{-1}\right.$ ) for $\mathrm{K} 40$, as per European Commission. The following equation was used to calculate (Din). 


\section{Military Technical College Kobry El-Kobbah, Cairo, Egypt}

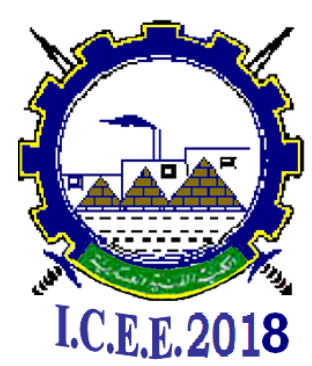

I.C.E.E.2018 $9^{\text {th }}$ International Conference on

Chemical \& Environmental Engineering

3-5 April 2018

$$
\text { Din }(\text { indoor })=0.92 \mathrm{ARa}+1.1 \mathrm{ATh}+0.08 \mathrm{Ak}
$$

Where, Din is indoor air absorbed gamma dose rate (nGy/h).

Indoor annual effective dose the indoor annual effective dose (Ein) received by a person is calculated on the basis of occupancy factor $(\mathrm{OF})$ and the conversion factor from indoor air absorbed gamma dose rate (Din) to effective dose. The time spent in the indoors (OF $=8760 \times 0.8 \mathrm{~h} / \mathrm{y})$ and conversion factor $(0.7 \mathrm{~Sv} / \mathrm{Gy})$ which is conversion factor of air absorbed gamma dose rate to effective dose received by average adult. For a person living in a building the Ein was calculated using the following equations:

Indoor Annual effective dose $($ Ein $)(\mathrm{mSv} / \mathrm{y})=\operatorname{Din}(\mathrm{nGy} / \mathrm{h}) \times 8760(\mathrm{~h} / \mathrm{y}) \times 0.8(\mathrm{OF}) \times 0.7$

$$
(\mathrm{Sv} / \mathrm{Gy}) \times 10-6 \text { (conversion from Nano to milli) }
$$

Excessive life-time cancer risk we live in a radioactive world with chances of getting cancer due to natural radiation. Indoor excessive life-time cancer risk:. Any excessive annual dose will increase a proportionate chance of ELCR. Based upon values of annual (Ein) estimated during current study; the ELCRin was calculated using the following equation[10].

$$
\operatorname{ELCR}(\text { in })=(\text { Ein }) \times \operatorname{LE} \times \mathrm{RF}
$$

Where, LE is the life expectancy is 70 years for person.

$\mathrm{RF}$ is fatal risk factor per Sievert that is 0.05 as per International Committee on Radiation Protection.

\subsubsection{Outdoor radiological hazard indices:}

Outdoor air gamma absorbed dose rate (Dout) for any area $1 \mathrm{~m}$ above the ground surface is calculated by converting the activities of Ra226, Th232 and K40 present in the environment into effective dose. Three conversion factors; $0.462\left(\mathrm{nGy} \mathrm{h}^{-1} / \mathrm{Bq} \mathrm{kg}^{-1}\right)$ for Ra226, $0.604\left(\mathrm{nGy} \mathrm{h}^{-1} / \mathrm{Bq} \mathrm{kg}^{-1}\right.$ ) for Th232 and $0.0417\left(\mathrm{nGy} \mathrm{h}^{-1} / \mathrm{Bq} \mathrm{kg}^{-1}\right.$ ) for K40 were used.

$$
\text { Dout }=0.462 \mathrm{ARa}+0.604 \mathrm{ATh}+0.0417 \mathrm{AK}
$$

Outdoor annual effective dose outdoor annual effective dose (Eout) is the radiation dose received by a person during one years' stay in the outdoor in any area. It is estimated from the net Outdoor air gamma absorbed dose rate (Dout), for the fraction of time of 
Military Technical College

Kobry El-Kobbah,

Cairo, Egypt

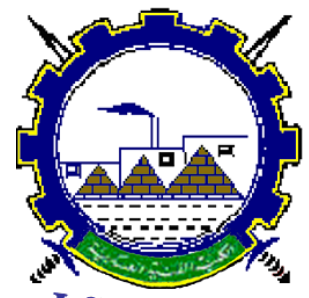

I.C.E.E.2018 $9^{\text {th }}$ International Conference

on

Chemical \& Environmental

Engineering

3-5 April 2018

stay in the outdoor $(\mathrm{OF}=8760 \times 0.2 \mathrm{~h} / \mathrm{y})$ and dose conversion factor $(\mathrm{CF}=0.7 \mathrm{~Sv} / \mathrm{Gy})$. The following equation has been used for the calculation of (Eout).

Outdoor Annual effective dose rate $($ Eout $)(\mathrm{mSv} / \mathrm{y})=($ Dout $)(\mathrm{nGy} / \mathrm{h}) \times 8760(\mathrm{~h} / \mathrm{y})$ $\times 0.2(\mathrm{OF}) \times 0.7(\mathrm{~Sv} / \mathrm{Gy}) \times 10-6($ conversion from Nano to milli)

Outdoor excessive life-time cancer risk (ELCRout) as described earlier is the chances of occurrence of cancer depend upon the annual effective dose (Eout), LE, age of a person and RF, fatal risk factor.The following equation was used to calculate the ELCRout [10].

$$
\operatorname{ELCR}(\text { out })=(\text { Eout }) \times \mathrm{LE} \times \mathrm{RF}
$$

Where, LE is the life expectancy is 70 years for person.

$\mathrm{RF}$ is fatal risk factor per Sievert that is 0.05 as per International Committee on Radiation Protection.

\subsection{Radium equivalent activity (Raeq), external and internal hazard Index (Hex, Hin)}

Radium equivalent activity is a widely hazard index used when comparing the specific activity of the samples containing different amounts of Ra226, Th232 and K40. It is supposed that $370 \mathrm{~Bq} / \mathrm{kg}$ of Ra226, $259 \mathrm{~Bq} / \mathrm{kg}$ of Th232 and $4810 \mathrm{~Bq} / \mathrm{kg}$ of $40 \mathrm{~K}$ produce the same dose rate of gamma rays. The maximum value allowed for public dose is 370 $\mathrm{Bq} / \mathrm{kg}[5]$.

$$
\mathrm{Raeq}=\mathrm{ARa}+1.43 \times \mathrm{ATh}+0.077 \times \mathrm{AK}
$$

To limit the annual external gamma-ray dose of the materials to $1.5 \mathrm{mSv} / \mathrm{y}$, for the samples under investigation, the external hazard index Hex is given by the following equation:

$$
\mathrm{Hex}=\mathrm{ARa} / 370+\mathrm{ATh} / 259+\mathrm{AK} / 4810<1
$$

The internal exposure to Rn222 and its radioactive progeny is controlled by internal hazard index, (Hin) which is given by equation:

$$
\mathrm{Hin}=\mathrm{ARa} / 185+\mathrm{ATh} / 259+\mathrm{AK} / 4810<1
$$




\section{Military Technical College \\ Kobry El-Kobbah, \\ Cairo, Egypt}

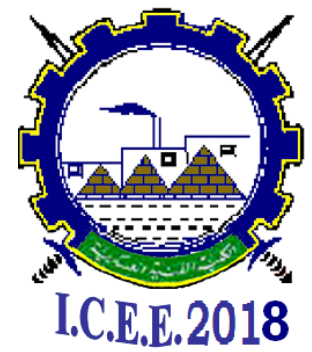

$9^{\text {th }}$ International Conference on

Chemical \& Environmental

Engineering

3-5 April 2018

\subsection{Activity indices (gamma-index (I $\gamma)$ and alpha index $(I \alpha)$ )}

Gamma index (IY) A number of gamma rays indices and evaluation indicators dealing with internal and external radiation originating from building materials it can be calculated according to (European Commission of Radiation Protection) as follow:

$$
(\mathrm{IY})=\mathrm{ARa} / 150+\mathrm{ATh} / 100+\mathrm{AK} / 1500
$$

To assess the exposure level due to radon inhalation originating from building materials, alpha indices have been proposed by (European Commission of Radiation Protection).The alpha index was determined using the following equation:

$$
(\mathrm{I} \boldsymbol{\alpha})=\mathrm{ARa} / 200
$$

\section{Conclusion}

Based on the analysis carried out for El-Dabaa site samples, it was observed that the average activity concentrations of $238 \mathrm{U}$ (226Ra) series, 232Th series and 40K are $28.1 \pm$ $1.01,11.5 \pm 0.35,15.4 \pm 0.6(\mathrm{~Bq} / \mathrm{kg})$ respectively and the average activity concentrations of the artificial $137 \mathrm{Cs}$ was found to be $0.9 \pm 0.03(\mathrm{~Bq} / \mathrm{kg})$.

Generally all The calculated Hazard indices in tables 3,4,5 and 6 are lower than the permissible international limits and the average values were to indoor hazard indices the air absorbed gamma dose rate (Din), the annual effective dose rate equivalent (Ein), excessive life-time cancer risk (ELCRin) was $39.74(\mathrm{nGy} / \mathrm{h}), 0.19(\mathrm{mSv} / \mathrm{y}), 0.682 \times 10-3$ respectively. With respect to the outdoor hazard indices the air absorbed gamma dose rate (Dout), the annual effective dose rate equivalent (Eout), excessive life-time cancer risk (ELCRout) they were 20.57 (nGy/h), 0.025 (mSv/y), 8.83×10-5 respectively. Concerning the radium equivalent, internal and external hazard indices the average values were found to be $45.73(\mathrm{~Bq} / \mathrm{kg}), 0.2,0.12$ respectively. The activity indices the gamma index and alpha index average results was $0.31,0.14$ respectively.

Finally, it can be concluded that the activity levels and calculated hazard indices of ELDabaa site are within the international recommended levels. These information and data are essential for emergency planning and environmental impact assessment of El-Dabaa nuclear power plant site. 
Military Technical College Kobry El-Kobbah, Cairo, Egypt

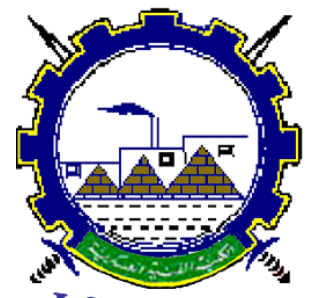

I.C.E.E.2018 $9^{\text {th }}$ International Conference on

Chemical \& Environmental

Engineering

3-5 April 2018

\section{References}

[1] Gilmore, G., Practical gamma-ray spectroscopy. 2011: John Wiley \& Sons.

[2] Ahmed, S.N., Physics and engineering of radiation detection. 2007: Academic Press.

[3] Ali, F.A., Measurements of naturally occurring radioactive materials (NORMs) in environmental samples. 2008, University of Surrey.

[4] Nguelem, E.J.M., M.M. Ndontchueng, and O. Motapon, Determination of 226Ra, $232 \mathrm{Th}, 40 \mathrm{~K}, 235 \mathrm{U}$ and $238 \mathrm{U}$ activity concentration and public dose assessment in soil samples from bauxite core deposits in Western Cameroon. SpringerPlus, 2016. 5(1): p. 1253.

[5] Abdel-Rahman, M.A. and S.A. El-Mongy, Analysis of radioactivity levels and hazard assessment of black sand samples from Rashid area, Egypt. Nuclear Engineering and Technology, 2017.

[6] Al-Sulaiti, H., et al., Determination of 137 Cs activity in soil from Qatar using highresolution gamma-ray spectrometry. Radiation Physics and Chemistry, 2016. 127: p. 222-235.

[7] El-Daly, T. and A. Hussein. Natural radioactivity levels in environmental samples in north western desert of Egypt. in Proceedings of the 3rd environmental physics conference. 2008.

[8] Radiation, U.N.S.C.o.t.E.o.A., Sources and effects of ionizing radiation: sources. Vol. 1. 2000: United Nations Publications.

[9] Radiation, U.N.S.C.o.t.E.o.A., UNSCEAR 2008. Sources and effects of ionizing radiation, 2010.

[10] Qureshi, A., et al., Assessment of radiation dose and excessive life-time cancer risk from the Bunair granite, northern Pakistan. Radiation protection dosimetry, 2017: $\mathrm{p}$. $1-9$. 
Military Technical College Kobry El-Kobbah, Cairo, Egypt

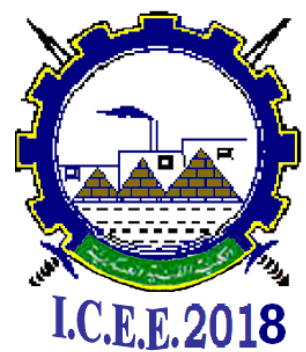

$9^{\text {th }}$ International Conference on

Chemical \& Environmental

Engineering

3-5 April 2018

Table (1) RGU-1 and RGTh-1 certificates values

\begin{tabular}{|c|c|c|c|c|c|}
\hline \multicolumn{3}{|c|}{ RGU-1 } & \multicolumn{3}{c|}{ RGTH-1 } \\
\hline analyte & Value & unit & analyte & Value & unit \\
\hline Th232 & 4 & $\mathrm{~Bq} / \mathrm{Kg}$ & Th232 & 3250 & $\mathrm{~Bq} / \mathrm{Kg}$ \\
\hline $\mathrm{U} 235$ & 228 & $\mathrm{~Bq} / \mathrm{Kg}$ & $\mathrm{U} 235$ & 3.6 & $\mathrm{~Bq} / \mathrm{Kg}$ \\
\hline $\mathrm{U} 238$ & 4940 & $\mathrm{~Bq} / \mathrm{Kg}$ & $\mathrm{U} 238$ & 78 & $\mathrm{~Bq} / \mathrm{Kg}$ \\
\hline $\mathrm{K} 40$ & 0.63 & $\mathrm{~Bq} / \mathrm{Kg}$ & $\mathrm{K} 40$ & 6.3 & $\mathrm{~Bq} / \mathrm{Kg}$ \\
\hline
\end{tabular}

Table (2): Soil samples results of analysis

\begin{tabular}{|c|c|c|c|c|c|c|}
\hline $\mathrm{Sn}$ & Latitude & longitude & ARa & ATh & AK & ACs \\
\hline NPPSs1 & 31.04326 & 28.51149 & $27.07 \pm 1.04$ & $11.19 \pm 0.45$ & $14.5 \pm 0.58$ & $1.11 \pm 0.04$ \\
\hline NPPSs2 & 31.04677 & 28.50769 & $30.53 \pm 1.11$ & $11.38 \pm 0.34$ & $14.18 \pm 0.53$ & $1.48 \pm 0.06$ \\
\hline NPPSs3 & 31.04978 & 28.50168 & $29.52 \pm 1.21$ & $14.93 \pm 0.52$ & $22.1 \pm 0.75$ & $0.63 \pm 0.02$ \\
\hline NPPSs4 & 31.05241 & 28.49472 & $29.33 \pm 1.02$ & $7.98 \pm 0.29$ & $8.88 \pm 0.32$ & $0.92 \pm 0.03$ \\
\hline NPPSs5 & 31.05526 & 28.48477 & $27.27 \pm 1.03$ & $9.96 \pm 0.33$ & $13.3 \pm 0.51$ & $0.64 \pm 0.03$ \\
\hline NPPSs6 & 31.05812 & 28.47775 & $24.87 \pm 1.1$ & $13.56 \pm 0.51$ & $19.62 \pm 0.72$ & $0.62 \pm 0.03$ \\
\hline \multicolumn{3}{|c|}{ Average value } & $28.1 \pm 1.01$ & $11.5 \pm 0.35$ & $15.4 \pm 0.6$ & $0.9 \pm 0.03$ \\
\hline \multicolumn{3}{|c|}{ Minimum value } & $24.87 \pm 1.1$ & $7.98 \pm 0.29$ & $8.88 \pm 0.32$ & $0.62 \pm 0.03$ \\
\hline \multicolumn{3}{|c|}{ Maximum value } & $30.53 \pm 1.11$ & $14.93 \pm 0.52$ & $22.1 \pm 0.75$ & $1.48 \pm 0.06$ \\
\hline \multicolumn{3}{|c|}{ World Average value } & $16-116(33)$ & $7-50(45)$ & $100-700(420)$ & - \\
\hline \multicolumn{3}{|c|}{$\begin{array}{l}\text { EL-Dabaa area average } \\
\text { results (old) }\end{array}$} & 22.12 & 10.01 & 180.04 & - \\
\hline
\end{tabular}

The abbreviations are as follow:

Ss- Soil samples

Sn-Sample number

NPP-Nuclear power plant area

AK-Activity concentration of $\mathrm{k} 40(\mathrm{~Bq} / \mathrm{Kg})$
ARa-Activity concentration of Ra226 (Bq/Kg) ATh-Activity concentration of Th232 (Bq/Kg) ACs- Activity concentration of Cs137 (Bq/Kg) 
Military Technical College Kobry El-Kobbah, Cairo, Egypt

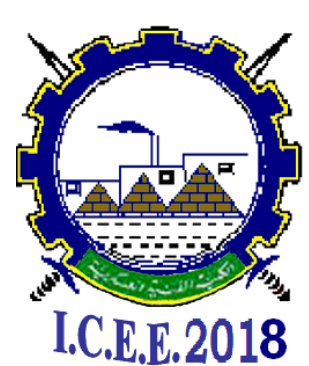

$9^{\text {th }}$ International Conference on Chemical \& Environmental Engineering 3-5 April 2018

Table (3): Results of indoor hazard indices due to the samples

\begin{tabular}{|c|c|c|c|c|c|}
\hline Sn & Latitude & longitude & Din & Ein & ELCRin \\
\hline NPPSs1 & 31.04326 & 28.51149 & 38.38 & 0.19 & $0.659^{*} 10^{-3}$ \\
\hline NPPSs2 & 31.04677 & 28.50769 & 41.75 & 0.2 & $0.717 * 10^{-3}$ \\
\hline NPPSs3 & 31.04978 & 28.50168 & 45.35 & 0.22 & $0.779 * 10^{-3}$ \\
\hline NPPSs4 & 31.05241 & 28.49472 & 36.48 & 0.18 & $0.626 * 10^{-3}$ \\
\hline NPPSs5 & 31.05526 & 28.48477 & 37.1 & 0.18 & $0.637 * 10^{-3}$ \\
\hline NPPSs6 & 31.05812 & 28.47775 & 39.37 & 0.19 & $0.676^{*} 10^{-3}$ \\
\hline \multicolumn{3}{|c|}{ Average value } & 39.74 & 0.19 & $0.682 * 10^{-3}$ \\
\hline \multicolumn{3}{|c|}{ Minimum value } & 36.48 & 0.18 & $0.626 * 10^{-3}$ \\
\hline \multicolumn{3}{|c|}{ Maximum value } & 45.35 & 0.22 & $0.779 * 10^{-3}$ \\
\hline \multicolumn{3}{|c|}{ World Average value } & 141 & 0.41 & $1.43 \times 10^{-3}$ \\
\hline
\end{tabular}

Table (4): Results of outdoor hazard indices for the samples

\begin{tabular}{|c|c|c|c|c|c|}
\hline $\mathrm{Sn}$ & Latitude & longitude & Dout & Eout & ELCRout \\
\hline NPPSs1 & 31.04326 & 28.51149 & 19.87 & 0.024 & $8.53 * 10^{-5}$ \\
\hline NPPSs2 & 31.04677 & 28.50769 & 21.57 & 0.026 & $9.26 * 10^{-5}$ \\
\hline NPPSs3 & 31.04978 & 28.50168 & 23.58 & 0.029 & $10.1 * 10^{-5}$ \\
\hline NPPSs4 & 31.05241 & 28.49472 & 18.74 & 0.023 & $8.04 * 10^{-5}$ \\
\hline NPPSs5 & 31.05526 & 28.48477 & 19.17 & 0.024 & $8.23 * 10^{-5}$ \\
\hline NPPSs6 & 31.05812 & 28.47775 & 20.5 & 0.025 & $8.8 * 10^{-5}$ \\
\hline \multicolumn{3}{|c|}{ Average value } & 20.57 & 0.025 & $8.83 * 10^{-5}$ \\
\hline \multicolumn{3}{|c|}{ Minimum value } & 18.74 & 0.023 & $8.04 * 10^{-5}$ \\
\hline \multicolumn{3}{|c|}{ Maximum value } & 23.58 & 0.029 & $10.1 * 10^{-5}$ \\
\hline \multicolumn{3}{|c|}{ World Average value } & 76.05 & 0.09 & $0.315 \times 10^{-3}$ \\
\hline
\end{tabular}


Military Technical College Kobry El-Kobbah, Cairo, Egypt

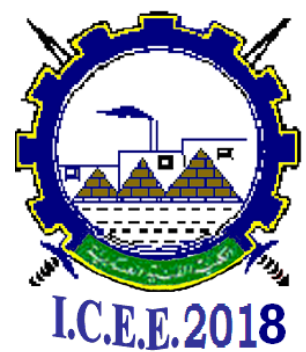

$9^{\text {th }}$ International Conference on

Chemical \& Environmental

Engineering

3-5 April 2018

Table (5): Results of Raeq, Hin and Hex calculations

\begin{tabular}{|c|c|c|c|c|c|}
\hline Sn & Latitude & longitude & Raeq & Hin & Hex \\
\hline NPPSs1 & 31.04326 & 28.51149 & 44.19 & 0.19 & 0.12 \\
\hline NPPSs2 & 31.04677 & 28.50769 & 47.9 & 0.21 & 0.13 \\
\hline NPPSs3 & 31.04978 & 28.50168 & 52.58 & 0.22 & 0.14 \\
\hline NPPSs4 & 31.05241 & 28.49472 & 41.43 & 0.19 & 0.11 \\
\hline NPPSs5 & 31.05526 & 28.48477 & 42.53 & 0.19 & 0.11 \\
\hline NPPSs6 & 31.05812 & 28.47775 & 45.77 & 0.19 & 0.12 \\
\hline \multicolumn{3}{|c|}{ Average value } & 45.73 & 0.2 & 0.12 \\
\hline \multicolumn{3}{|c|}{ Minimum value } & 41.43 & 0.19 & 0.11 \\
\hline \multicolumn{3}{|c|}{ Maximum value } & 52.58 & 0.22 & 0.14 \\
\hline \multicolumn{3}{|c|}{ Maximum limit } & $<370$ & $<1$ & $<1$ \\
\hline
\end{tabular}

Table (6): Results of (gamma-index (I $\left.{ }^{\mathbf{Y}}\right)$ and alpha index (I $\left.{ }^{\boldsymbol{\alpha}}\right)$ )

\begin{tabular}{|c|c|c|c|c|}
\hline Sn & Latitude & longitude & (I $\mathbf{Y})$ & $($ I $\boldsymbol{\alpha})$ \\
\hline NPPSs1 & 31.04326 & 28.51149 & 0.3 & 0.135 \\
\hline NPPSs2 & 31.04677 & 28.50769 & 0.33 & 0.152 \\
\hline NPPSs3 & 31.04978 & 28.50168 & 0.36 & 0.148 \\
\hline NPPSs4 & 31.05241 & 28.49472 & 0.28 & 0.147 \\
\hline NPPSs5 & 31.05526 & 28.48477 & 0.29 & 0.136 \\
\hline NPPSs6 & 31.05812 & 28.47775 & 0.31 & 0.124 \\
\hline \multicolumn{3}{|c|}{ Average value } & 0.31 & 0.14 \\
\hline \multicolumn{3}{|c|}{ Minimum value } & 0.28 & 0.124 \\
\hline \multicolumn{3}{|c|}{ Maximum value } & 0.36 & 0.152 \\
\hline \multicolumn{3}{|c|}{ Maximum limit } & $<1$ & $<1$ \\
\hline
\end{tabular}




\begin{tabular}{|l|c|}
\hline Proceeding of the $9^{\text {th }}$ ICEE Conference 3-5 April 2018 & NRA \\
Military Technical College \\
Kobry El-Kobbah, \\
Cairo, Egypt
\end{tabular}

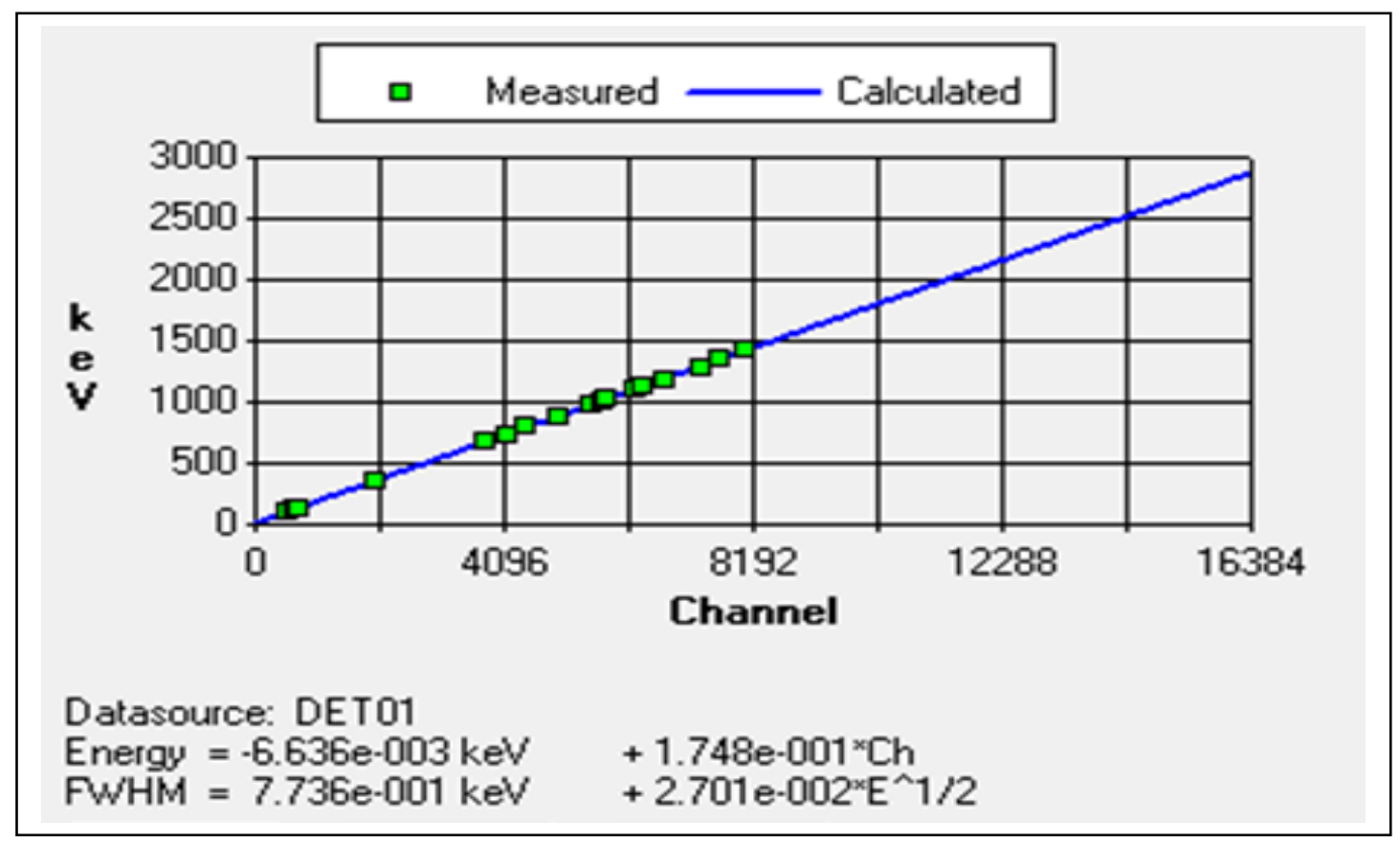

Figure (2.1): Energy calibration curve 


\begin{tabular}{|c|c|}
\hline Proceeding of the $9^{\text {th }}$ ICEE Conference 3-5 April 2018 & NRA \\
Military Technical College \\
Kobry El-Kobbah, \\
Cairo, Egypt
\end{tabular}

Efficiency Calibration Curves

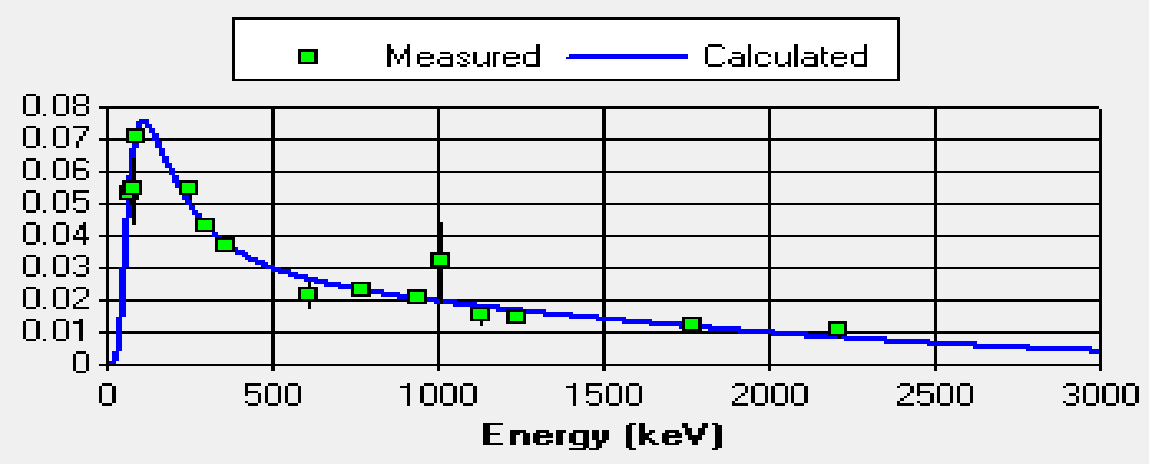

Datasource: C: \GENIE2K VOMARYRGUYRGU 1nd count 1-10-2017[24hrs].CNF $\ln [E f f]=-4.045 e+000+7.471 e-001{ }^{*} x \quad-3.766 e-001^{\wedge} x^{\wedge} 2+3.883 e-001^{*} x^{\wedge} 3$ where: $x=\ln [1.134 \mathrm{e}+003 / \mathrm{E}]$

Figure (2.2): Efficiency calibration curve for (RGU-1) using Genie2000 